\title{
Erratum to: Trends in the classical biological control of insect pests by insects: an update of the BIOCAT database
}

\author{
Matthew J. W. Cock - Sean T. Murphy $\cdot$ Moses T. K. Kairo $\cdot$ Emma Thompson • \\ Rebecca J. Murphy $\cdot$ Antonio W. Francis
}

Published online: 15 June 2017

(C) International Organization for Biological Control (IOBC) 2017

\section{Erratum to: BioControl (2016) 61:349-363 DOI 10.1007/s10526-016-9726-3}

In editing the figures following acceptance, Fig. 1 was inadvertently substituted with a figure from a different analysis. The correct figure is shown below. The text needs no adjustment as it was written and reviewed using the correct figure.

In Table 1, line 4, a spreadsheet error means that the number of biological control agents (BCAs) in

The online version of the original article can be found under doi:10.1007/s10526-016-9726-3.

M. J. W. Cock $(\bowtie) \cdot$ S. T. Murphy · E. Thompson ·

R. J. Murphy

CABI, Bakeham Lane, Egham, Surrey TW20 9TY, UK

e-mail: m.cock@cabi.org

\section{S. T. Murphy}

e-mail: s.murphy@cabi.org

E. Thompson

e-mail: e.thompson@cabi.org

R. J. Murphy

e-mail: r.murphy@cabi.org

M. T. K. Kairo

School of Agricultural and Natural Sciences, University of Maryland Eastern Shore, Suite 3055, Richard A. Hazel Hall, Princess Anne, MD 21853, USA

e-mail: mkairo@umes.edu
BIOCAT2010 should have read 2171, not 2384. Hence, the abstract should refer to 2171 different insect biological control agents, and the first line of text on p. 354, should state that the increase in the number of different BCAs used increased by nearly $8 \%$ not $19 \%$. Further, the derivation of this number was not exactly as set out in the methods, which state that each unique combination of BCA genus and species was counted as one species. Insert after the second sentence under point 4 on p. 352:

Accordingly, BCA species released and documented with a genus name but not a species name (e.g. as Encarsia sp. or Encarsia spp.) were handled

\footnotetext{
A. W. Francis

Florida Department of Agriculture and Consumer

Services, Division of Plant Industry, Bureau of Methods

Development \& Biocontrol, 2725 S. Binion Road,

Apopka, FL 32703, USA

e-mail: antonio.francis@freshfromflorida.com
} 


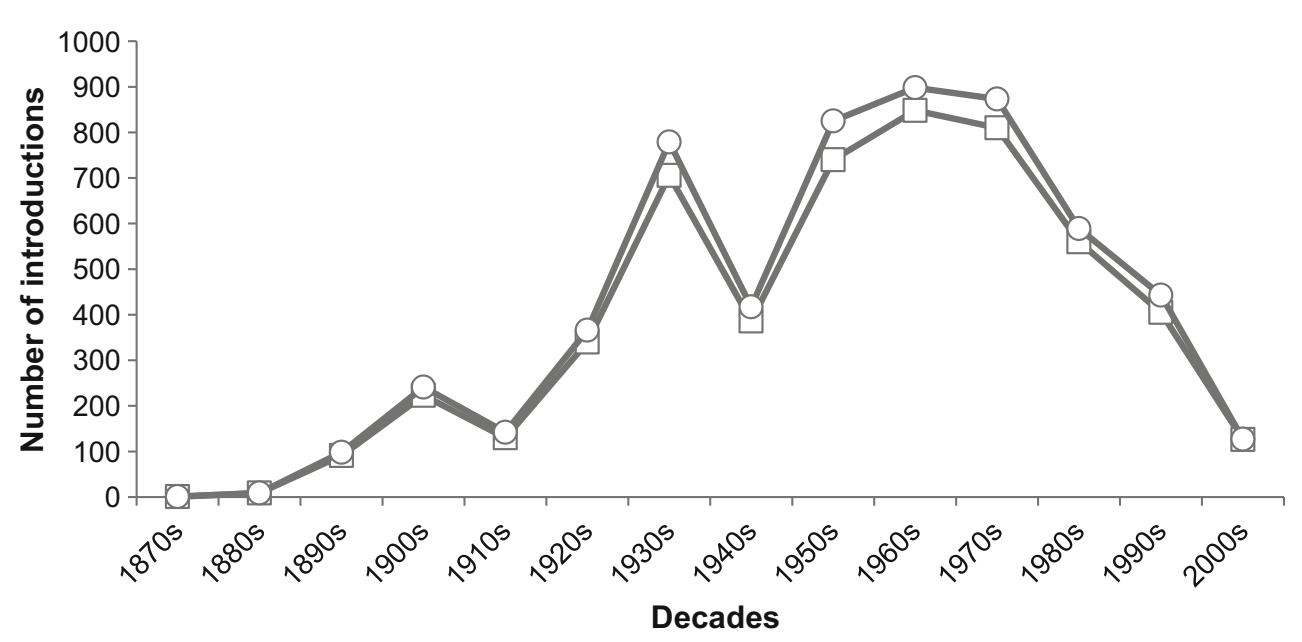

Fig. 1 The number of introductions of biological control agents each decade counted using mode 1 (squares) and mode 2 (circles)

differently. Rather than treat all releases of Encarsia sp. as just one BCA species, the records were further analysed and each different target genus was assumed to have been targeted by a different Encarsia species. Thus in this extreme example, there were 27 releases of Encarsia sp. against 15 different target genera and four releases of Encarsia spp. against four different target genera, so it was estimated that 19 different species of Encarsia were released as Encarsia sp. or Encarsia spp. 